\title{
Differential water footprint assessment - conventional versus paste tailings disposal
}

\author{
A Fernandez-Iglesias ArcelorMittal Global R\&D Asturias, Spain
}

S Andres ArcelorMittal Global R\&D Asturias, Spain

R Luiña University of Oviedo, Spain

D Pecharroman University of Oviedo, Spain

V Alvarez-Cabal University of Oviedo, Spain

\begin{abstract}
In August 2014, the international standard ISO 14046:2014 'Environmental management - Water footprint - Principles, requirements and guidelines' (International Organization for Standardization [ISO] 2014) was released. This is the first version ever published on water footprint, and therefore an important milestone for all environmental activities related to water management.

The issue of water and its management has become increasingly central to the global debate on sustainable development. This interest has been driven by growing water demand, increasing water scarcity in many areas and/or degradation of water quality. This drives the need for a better understanding of water related impacts as a basis for improved water management at local, regional, national and global levels.

It is therefore desirable to have appropriate assessment techniques that can be used in an internationally consistent manner. One of the techniques being developed for this purpose is the water footprint assessment (ISO 2014).

Water and mining have always had a close connection because most mining and mineral processing operations require water, often in large amounts (Rowe 2012). Mining activities can contaminate surface and groundwater and demand great amounts of water, especially froth process used as a method of minerals separation. There are some minerals such as coal, cyanide or bauxite that can severely affect freshwater resources. Moreover, closure stage requires special treatments because of significant long-term environmental liabilities - they must be pumped and treated indefinitely to prevent contamination of surface and ground waters (Hendrix 2012). Despite of the fact that mining represents a very small fraction of the total world's water demand, its impact on local resources surrounding mine sites can be significant. The problem is that mining operations cannot be relocated, making the sector susceptible to changing local water availability (Barton 2010).

Paste and thickened tailings technology is nowadays a proven solution for one of the biggest environmental impacts of mining activities: tailings disposal. Among the various drivers that this technology has, water is probably one of the most important, not only from an environmental perspective but also from an economic one.

This paper applies the methodology proposed by the Water Footprint Network International and later published as an ISO norm, to assess the differential Water Footprint of two scenarios, conventional tailings management and its alternative process, paste and thickened tailings.
\end{abstract}

\section{Introduction}

Satisfying the demand for higher living standards is heavily dependent upon mineral products from expanded mining activities (Society for Mining, Metallurgy and Exploration, Inc. [SME] 2012). On the other 
hand, water and mining have always had a close connection because most mining and mineral processing operations require water, often in large amounts (Rowe 2012).

National and international reforms, company commitment to industry sustainability and best practice codes, investors, governments and communities are all increasing the need to better understand the nature of interactions with water resources. Lifecycle assessment (LCA) is an internationally standardised framework for assessing environmental impacts of products and processes (ISO 2006). LCA provides a means of understanding both direct impacts occurring at individual production sites, as well as indirect impacts associated with processes occurring in supply chains. Generally, applications of LCA to mining and primary metal production systems have focussed on issues such as quantifying energy consumption and greenhouse gas emissions (Norgate and Jahanshahi 2010; Eckelman 2010) or developing measures of resource depletion (Klinglmair et al. 2013). In contrast, there have been few studies that have considered both the direct and indirect water use of these production systems (Northey et al. 2014).

Mining activities can contaminate surface and groundwater and demand great amounts of water, especially foam process used as a method of minerals separation. There are some minerals such as coal, cyanide or bauxite that can severely affect freshwater resources. Moreover, closure stage requires special treatments because of significant long-term environmental liabilities - they must be pumped and treated indefinitely to prevent contamination of surface and ground waters (Hendrix 2012).

Due to these facts, it can be said that the mining sector depends on high volumes of water. This in turn means a danger of water scarcity. Despite this, mining represents a very small fraction of the total world's water demand, but its impact on local resources surrounding mine sites can be significant. The problem is that mining operations cannot be relocated, making the sector susceptible to changing local water availability (Barton 2010).

In arid regions, where water resources are limited, the great volumes of water demanded by mining operation may be a significant concern. On the opposite side, in wet climates, excess water may hinder the system operation and generates certain problems in specific activities such as drainage at closure stage.

Water is a vital natural resource for all ecosystems, human wellbeing, and many economic activities. Because of the combination of population growth and economic development leading to increasing human freshwater use (Vörösmarty et al. 2000) and enhanced climate change effects on the global water cycle, water scarcity is becoming an increasing environmental concern. Although freshwater is a local resource, water scarcity is leading to the threat of a global water crisis, with a large share of global population being affected (United Nations World Water Assessment Programme 2009; Kounina et al. 2013).

Fresh water is a precious resource on our planet; it is crucial to sustain life and cannot be replaced by any other substance. In terms of ecosystems, water scarcity can affect biodiversity, as sensitive species may not be able to cope with reduced freshwater availability (Berger \& Finkbeiner 2010). In 2025 it is estimated that approximately 1.8 billion people will live in areas of absolute water scarcity. With increasing population, changing consumption patterns and the additional pressures exerted by climate change is expected to have greater difficulty to satisfy water demand (Zarate \& Kuiper 2013).

Mining companies have the management and financial resources to play a leading role in developing and applying sustainable water management practices. They have developed several techniques to reduce, conserve and recycle water from mining processes and to connect it to meet other needs. Some techniques include using saline water, groundwater pumped from mining excavations, re-use and recycling of water, returning water to surface water or to ground water, and preventing acid mine drainage (Hendrix 2012).

Thickening is presented as a technique that allows re-use and recycling of water in foam process. This process produces a large amount of inert materials called tailings or tails, which contain great volumes of water and they are generally deposited in ponds without having any utility. By thickening, it is possible to recover part of this water contained in tailings saving water use in foam process and land use in tailings embankments. 
To know how much more sustainable thickened tailings are versus conventional management, lifecycle assessment methodology is not enough if water degradation and consumption is dismissed. The water footprint appears as the solution required (Fernández-Iglesias et al. 2013).

The water footprint approach developed by Hoekstra et al. (2009) is one of the most widely used. It is very similar to the carbon footprint. However, on August 2014, the International Organization Institute published the new standard about water footprint (ISO 2014). This is an important milestone in the water footprint assessment and in the sustainability assessment in general.

\section{$2 \quad$ Water footprint methodology}

Throughout the years, there has been development of different methodologies, approaches and indicators to assess the vulnerability of water resources; however, it has been difficult to reach consensus. In fact, they are still in development. The problem has been that there are different facets equally important when making an assessment (water use, availability, scarcity etc.) (Brown \& Matlock 2011).

At the beginning, all the interest was focused on counting the water consumption and the emission of waste water directly on site in order to maximise operations efficiency. In this way, the amount of water was evaluated but not the impacts related (Gerbens-Leenes \& Hoekstra 2008).

The first steps towards developing a methodology for assessing the water footprint were done by Hoekstra (2003). His proposal is the most widespread. The base of it was the same idea as the carbon footprint but evolved independently from the LCA. It comes down to a quantification of the water used in an aggregate without reflecting the potential impact, both environmental and social, which may have water use form (Jeswani \& Azapagic 2011).

\subsection{Lifecycle assessment and water footprint}

The methodology of lifecycle assessment has been the way to evaluate the products and processes sustainability. However, it had some weakness, as considering the use of water. This problem had been derived from both, the lack of information on water flows in the databases and the lack of characterisation factors to translate these flows into impacts (Jeswani \& Azapagic 2011; Koehler 2008). This can be explained by the history of LCA, which was developed in industrial countries that usually do not suffer from water scarcity (Berger and Finkbeiner 2010). In addition, impacts due to water use are dependent on location and time, but LCA uses global values.

In general, most LCA studies that report water use simply report the total input without differentiating between the in-stream and off-stream uses or between freshwater and seawater; freshwater availability varies around the globe, different watercourses fulfil different ecological functions, and different water qualities enable different uses (Berger \& Finkbeines 2010).

Currently, there are factors that assess freshwater consumption considering the cause-effect as those developed by Milà i Canals et al. (2009), Motoshita et al. (2010), Pfister et al. (2009), Kounina et al. (2013), Jeswani and Azapagic (2011). Furthermore, on August 2014, the International Organization for Standardization published the standard 14046 (ISO 2014) about how to conduct a water footprint assessment in the best way. This standard aims to provide a framework to ensure consistency in the way that water footprints are conducted and presented, while also reinforcing the need for a lifecycle approach (Northey et al. 2014). It is a proactive measure for supply chain management to be one step ahead and have information available for these assessments to become a reality (Triantou 2009).

\subsection{Water footprint approaches}

There is a close relationship between water consumption and other environmental and social issues such as land use systems, climate change and demographic change. Therefore, assessing the impact of water consumption must be both global and regional (Hoekstra 2011). 
Different agencies and authors have attempted to address this problem by developing tools to measure and evaluate the use of fresh water. Some proposals are the water footprint network (WFN), The Milà $i$ Canals et al. (2009), Pfister et al. (2009), the World Business Council for Sustainable Development (World Business Council for Sustainable Development [WBCSD] 2010), United Nations Environment Programme (UNEP)/Society of Environmental Toxicology and Chemistry (SETAC) and International Organization for Standardization (ISO).

The water footprint network introduced the water footprint indicator in 2002 in order to calculate the relation between human consumption and water usage as well as between global trading and water resource management (Hoekstra \& Chapagain 2008).

It is an analytical tool that can help to understand how activities and products are related to water scarcity and pollution and what can be done to make sure activities and products do not contribute to unsustainable use of freshwater. As a tool, it does not tell people what to do; rather, it helps people to understand what can be done (Hoekstra et al. 2011).

The water footprint concept was introduced by Hoekstra, who belongs to WFN, from the concept of virtual water. Since then it has evolved and defined as a method of evaluation of the water used by a product, service or country (Hoekstra \& Chapagain 2008; Hoekstra et al. 2009; Water Footprint Network 2011).

In this approach, the water footprint represents the sum of all the water used in a supply chain, comprising blue, green and grey water. Blue water is defined as the volume of freshwater abstracted from rivers, lakes and aquifers. Green water corresponds to the amount of rainwater used by plants. Grey water represents water required to dilute discharged water to background pollutant concentrations (Jeswani \& Azapagic 2011).

The Milà i Canals et al. (2009) approach considers water use at the level of a river basin. This method recommends to account in the Life Cycle Inventory (LCI) both the source of water and the type of use. As far as the source is concerned, Milà I Canals et al. (2009) follow the same criteria as Hoekstra, who ranks as blue and green water. Blue water can be divided into flow (river/lake), fund (aquifer) and stock (fossil). The water use could be evaporative and non-evaporative. The last one is the water that, once it is used, returns to the freshwater source to be used again.

Milà I Canals et al. (2009) suggest that the green water and the non-evaporative use of river, lake, and aquifer water has no relevant impacts, so it is not necessary to take into account in the Life Cycle Inventory Assessment (LCIA). But they propose to account the relationship between land use and rainwater availability, because changes in land use imply changes in infiltration and evapotranspiration.

Pfister et al. (2009) define water footprint as the sum of consumption multiplied by the rate of local water stress. The impact of the use of water is assessed as physical exhaustion of the water contained in a store and the degradation of water systems due to changes in water quality.

This method involves several differences to the approach of Milà et al. (2009). The latter propose an evaluation on a larger scale, at the basin level. It is just considered blue water but it is distinguished as three categories of water use: in-stream water use, water consumption (where the water is no longer available in the watershed) and water-quality degradation.

In addition, the water poured into another basin is classified as loss and the wastewater discharged is treated as a loss of water quality (although it does not specify how).

\subsection{ISO 14046:2014}

This standard was published on 31 of July, under the title of 'Environmental management - Water footprint - Principles, requirements and guidelines'. It specifies principles, requirements and guidelines related to water footprint assessment of products, processes and organisations based on lifecycle assessment (LCA). 
This standard follows the same pattern as the carbon footprint, but it is much more complex. The approach, developed in ISO, is based on examination of environmental and human health impacts; it includes geographical and temporary dimensions and identifies the quantity of direct and indirect water used and changes in water quality. It is the definitive definition of water footprint. The ISO approach stresses that water footprint is an impact, not a volume or an inventory. As the water footprint is a local indicator, regional water scarcity or water stress should be determined (VTT Technical Research Centre of Finland 2014).

The standards allow assessment of the magnitude of potential environmental impacts related to water, identification of the 'hotspots' to reduce them and facilitate water efficiency, and optimisation of water management at product, process and organisations. Moreover, the water footprint results allow tracking over time and the application of technology benchmarking related to process-water.

It could be an independent assessment or as part of a more comprehensive environmental assessment.

The standard says that water footprint is the result of a comprehensive assessment that results in a profile of impact category indicator results. The stages included are:

- Goal and scope definition. Define and describe the product, process or activity. Establish the context in which the assessment is to be made and identify the boundaries and environmental effects to be reviewed for the assessment.

- Water footprint inventory analysis. Include inputs and outputs from each unit process being part of the system to be studied. Any discrepancies in the inventory balance shall be explained and information on each elementary flow should generally include, where relevant (quantities of water used, resource types of water used, water quality parameters and/or characteristics, forms of water use, temporal aspects of water use, emissions to air, water and soil that impact water quality).

- Water footprint impact assessment. Represented by one or more parameters that quantify the potential environmental impacts of a product system, process or organisation related to water, including the water footprint indicator result related to one single impact category or the water footprint profile, which comprises several indicator results.

- Interpretation. Identify the significant issues based on the results of the water footprint assessment; evaluate the completeness, sensitivity and consistency checks; consider geographical and temporary aspects; conclude the water footprint assessment; describe the limitations of the water footprint assessment; apply a qualitative and/or quantitative assessment of uncertainty; consider a sensitivity analysis to provide ranges around the reported results.

However, information on water use in databases is still limited. Databases such as GaBi and ELCD differ only the source of water, while Ecoinvent also includes additional streams based on water use. This problem of lack of information on water flows also appears in impact evaluation parameters. In fact, most reports evaluating lifecycle water use only report total water input, without differentiating between in-stream, off-stream, fresh water and sea water.

The greatest progress in this regard is in the latest versions of the Ecoinvent database and SimaPro software. Ecoinvent V.3 incorporates part of the regionalised flows, whereas SimaPro 8 allows one to choose between different water use impact assessment methods, both intermediate and final categories. However, there is still a long way to go to improve the consistency of the studies using the standard 14046. 


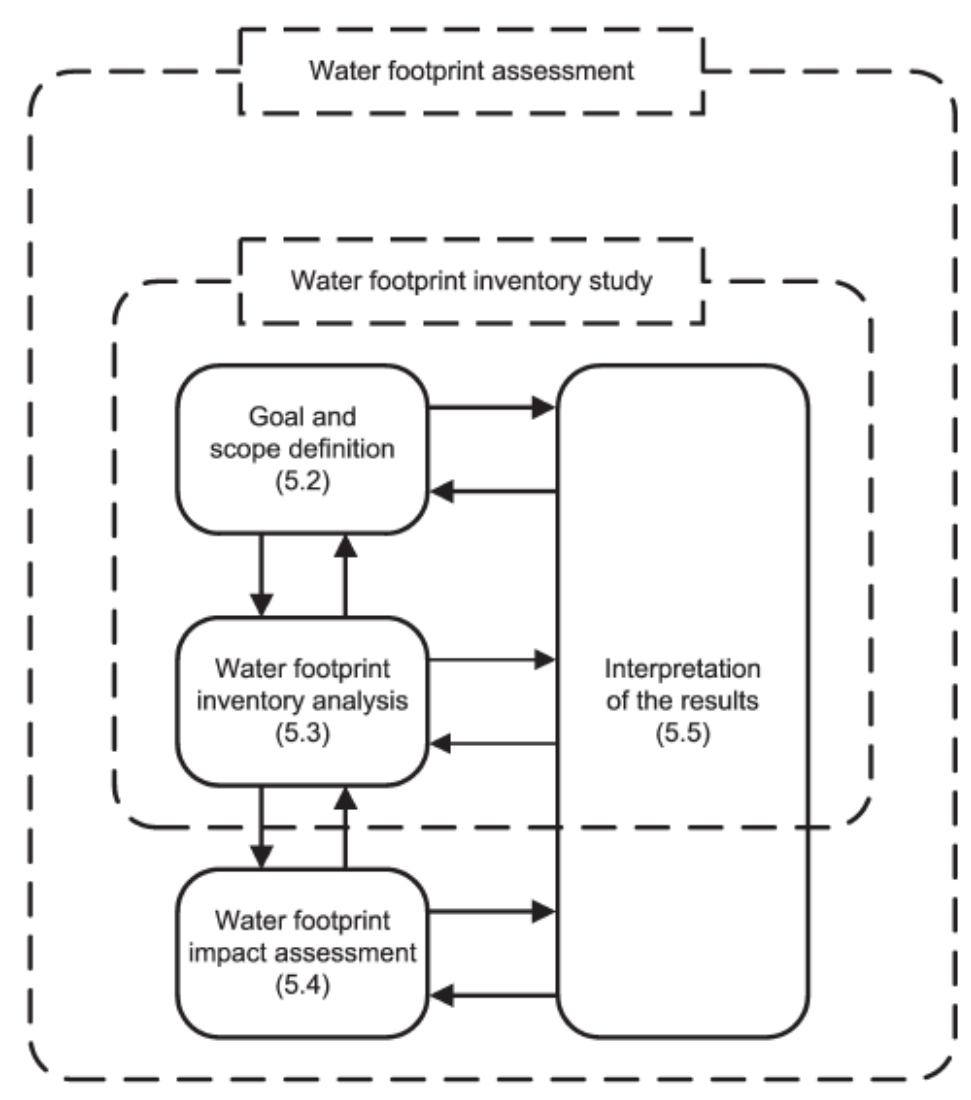

Figure $1 \quad$ Phases of a water footprint assessment (ISO 2014)

\section{Scarcity water footprint of tailings management}

Despite the significant consumption of water in the mining process, there are few studies evaluating the sustainability of these depending on water availability. The method used so far is that developed by Hoekstra et al.; however, there are some limitations. For example, the calculation method of grey water cannot account for discharge of pollutants that have no background level in the receiving water (Northey et al. 2014).

On the other hand, ISO standard 14046 recommends taking into account both water depletion and water quality degradation to assess the whole water footprint of a product, process or organisation. Otherwise, it is necessary to specify it (ISO 2014).

Due to the currently databases updated problems, this report is going to assess the scarcity water footprint. Moreover, in the extraction of iron ore there are several associated several chemicals (foaming and flocculants) that are not water soluble, so they are not pollutants. In fact, the iron ore tailings could be discharged into rivers without any risk of contamination but it is not allowed because of the great volume of water which could alter the ecosystem. Therefore, these tailings should preferably be contained in a sealed dam with geotextile, so seepage is considered zero.

\subsection{Goals and scope}

The extraction process of iron ore, as well as other minerals, requires a large amount of water. Due to the water scarcity and the impact on sustainable management, it is necessary to use the best available techniques in mining process. The thickened tailings technique is a very significant water savings technique. It also reduces the occupation of land and facilitates closure and rehabilitation stages.

Improvements in the sustainability of the process because of thickened tailings will be more or less relevant depending on the location of the mine. Therefore, the aim of this assessment is to compare the water footprint of two scenarios, which are two different ways of managing one of the main wastes of mineral 
extraction process. And they are going to be situated in two different localisations: Minas Gerais in Brazil and Atacama in Chile.

- Scenario 1: Conventional tailings management. The tailings slurry is conventionally discharged with a considerable quantity of process water into a settling pond ( $30 \%$ solids concentration).

- Scenario 2: Alternative tailings management. The tailings slurry is thickened from $30 \%$ to $60 \%$ before discharge into a pond.

The alternative scenario allows the recirculation of a large quantity of water, which means an additional saving of water that is incorporated in the mineral processing plant. Water recycling is defined as the onsite reuse of water for the same purpose.

The functional unit is expressed as water volume per unit of time, so it has been taken as a unit to carry out calculations $\mathrm{m}^{3} /$ year.

\subsubsection{Scenarios}

In Scenario 1, the tailings slurry is conventionally discharged with a considerable quantity of process water into a settling pond. In general, tailings beach slopes are below $0.5 \%$ in the disposal area. The solids concentration is $30 \%$ by mass.

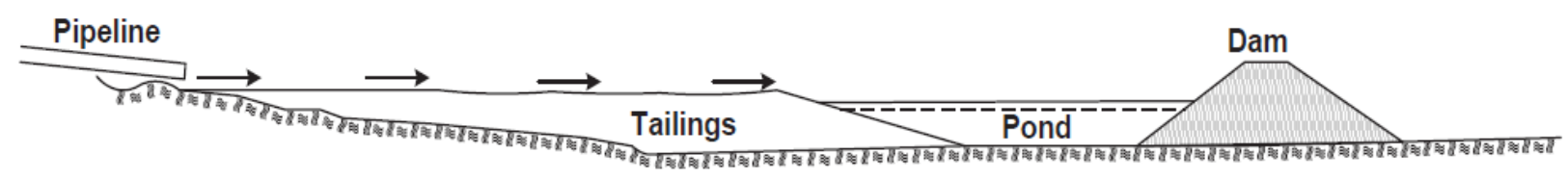

\section{Figure 2 Conventional tailings disposal system}

It corresponds to the reference scenario, which studies the impact generated by the traditional way of storage of waste from the extractive mining.

The disposal of tailings is the second major impact of mining activities (Kulczycka 2008), even for non-toxic waste such as extraction of iron ore.

This stage comprises a stage in which the residual material from the flotation process for obtaining the ore is pumped to the discharge point. Even if there are examples of direct discharges into the river, there are specific recommendations to change this practice by adopting less aggressive techniques. Therefore, in this case study it will evaluate the discharge and storage in a settling pond.

In Scenario 2, a thickening tailings technique has been evaluated, which begins, as in the previous case, after the flotation tank (Peck 2007; Jewell \& Fourie 2006) with a tailings system that includes a thickener that produces a highly concentrated underflow. On flat terrain, the thickened tailings are discharged from an artificial ramp or a tower forming a ridge or cone. It may be favourable to locate the thickener close to the disposal area when deposition takes place along a hill side or down a valley (Wennberg 2010).

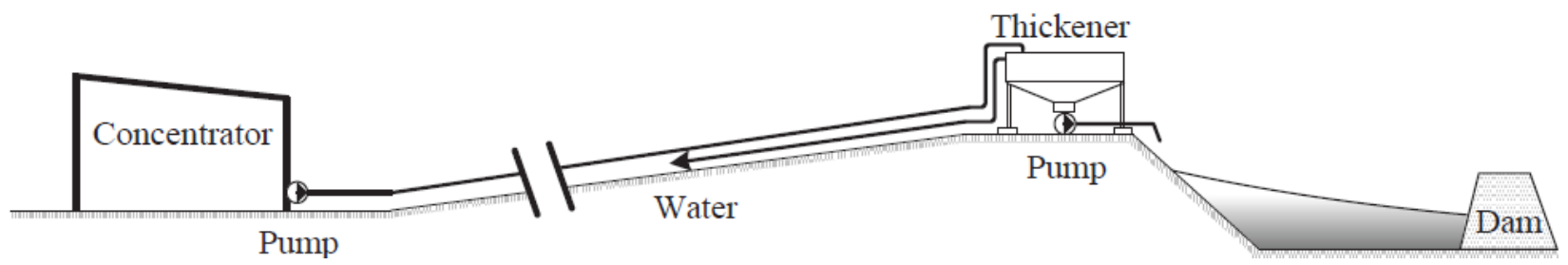

Figure 3 Thickened tailings system with the thickener located on a hill close to the disposal area

With an elevated location of the thickener close to the disposal area only short distance pumping of thickened slurry is initially required. With a thickened tailings system up to $75 \%$ of process water can be recycled directly from the overflow of the thickener. The solids concentrations by volume will be above 
$60 \%$ to achieve paste properties that allows slope of deposited tailings of $2 \%$ with no segregation of particles and virtually no drainage of water (Wennberg 2010).

\subsubsection{Localisation and climatology of the mine}

One of the mine will be located at $20^{\circ} 08^{\prime}$ south, $44^{\circ} 24^{\prime}$ west in Minas Gerais (Brazil), approximately 52 kilometres southwest of Belo Horizonte, in São Francisco Basin.

The climate of Minas Gerais is classified as tropical, with mild temperatures throughout the year. Moisture in Belo Horizonte is moderate, around 65\%. The precipitation is mainly focused on the warmer months, from October to March.

The water footprint assessment required potential evapotranspiration and precipitation data. Such data has been extracted using the New_LocClim program, which makes an interpolation to the desired coordinates, taking into account existing climate data and stations. The program includes average monthly climatic data between 1961 and 2000. For Minas Gerais, the annual precipitation is $1,479 \mathrm{~mm}$ and the annual potential evapotranspiration is $1,860 \mathrm{~mm}$.

\subsubsection{Assumptions}

To carry out the accounting water footprint, assumptions have been made throughout the assessment:

- Since this is a comparison between two processes, it will only take into account the different phases comprising the management and disposal of tailings.

- It has considered a mine's lifetime of 30 years (Doka 2009), operating $7.200 \mathrm{~h} /$ year. During this period of time, water is being consumed and tailings are being produced.

- Transport of tailings in both cases is performed by pipelines, so there are no losses by evaporation.

- In both scenarios, it is built as a down-valley pond, insulated with geomembrane. It is therefore accepted that there is no water leakage, soil or contributions from it to the pond. Losses would exist only by evaporation.

\subsubsection{Data}

Data quality shall be composed of accuracy (i.e. representativeness and methodological appropriateness and consistency), precision/uncertainty and completeness of the inventory (ISO 2006). For this case of study, data collected shall be derived from a model where the flow values are calculated for an output flow at the process plant of $500 \mathrm{~m}^{3} / \mathrm{h}$.

\subsubsection{Cutoff criteria}

Cutoff criteria refer to the omission of not relevant lifecycle stages, activity types, specific processes and products, and elementary flows from the system model. Cutoffs are quantified in relation to the percentage of environmental impacts that is approximated to be excluded via the cutoff (JRC-ies 2010).

The indirect water consumed, related to facilities and cleaning operations, is left outside the scope of study because it is equivalent in both scenarios. There is only one element that differs, being exclusive of the Scenario 2: the thickener. The cutoff criteria of this study permit the exclusion of the indirect water consumed in thickener manufacturing and in the energy used in the thickening and transport process because they represent less than $3 \%$ of the total water managed in the model.

\subsection{Water footprint inventory analysis}

Water footprint inventories are an account of the significant inputs and outputs of water to a process. In this paper, data comes from a model and does not account for emissions, as explained above. It will be compared with the water flows of both scenarios, starting from the point at which they are different. 
Therefore, the process starts at the downstream mineral treatment plant and finishes at the tailings disposal facilities. In both scenarios, there is a return water flow from the tailings disposal facilities to the mineral treatment plant, where it is recycled. But only in Scenario 2 is there another return water flow from the thickener to the mineral treatment plant that it is recycled too. Those return flows that are recycled reduce the water input into de mineral treatment plant; therefore, the water depletion is reduced.

Apart from that, there are losses of water as evaporation flow from the pond. Due to Scenario 1 (a conventional disposal tailings), the pond will be bigger than Scenario 2 and the evaporation will be higher.

The water evaporated calculation is based on the evaporation in a specific area. Through the New_LocClim program it has been obtained climatological values related to potential evapotranspiration (PTE) and the precipitation, evaporation will be the difference between one and another variable.

\subsubsection{Water flows for Scenario 1}

In the conventional scenario, the flow of tailings coming from the process plant is $500 \mathrm{~m}^{3} / \mathrm{h}$, where $437 \mathrm{~m}^{3} / \mathrm{h}$ is water. This flow is sent to the tailings pond. Some of the water deposited will be evaporated $\left(80.54 \mathrm{~m}^{3} / \mathrm{h}\right)$, another part is reclaimed to the process plant $\left(290 \mathrm{~m}^{3} / \mathrm{h}\right)$, and another will be retained $\left(112 \mathrm{~m}^{3} / \mathrm{h}\right)$. To calculate the evaporation, a precipitation value of $1,479 \mathrm{~mm} /$ year has been considered, an evapotranspiration value of $1,860 \mathrm{~mm} /$ year and a surface pond of 185.19 ha. As a result, the conventional method needs $2,088,445 \mathrm{~m}^{3}$ of fresh water per year.

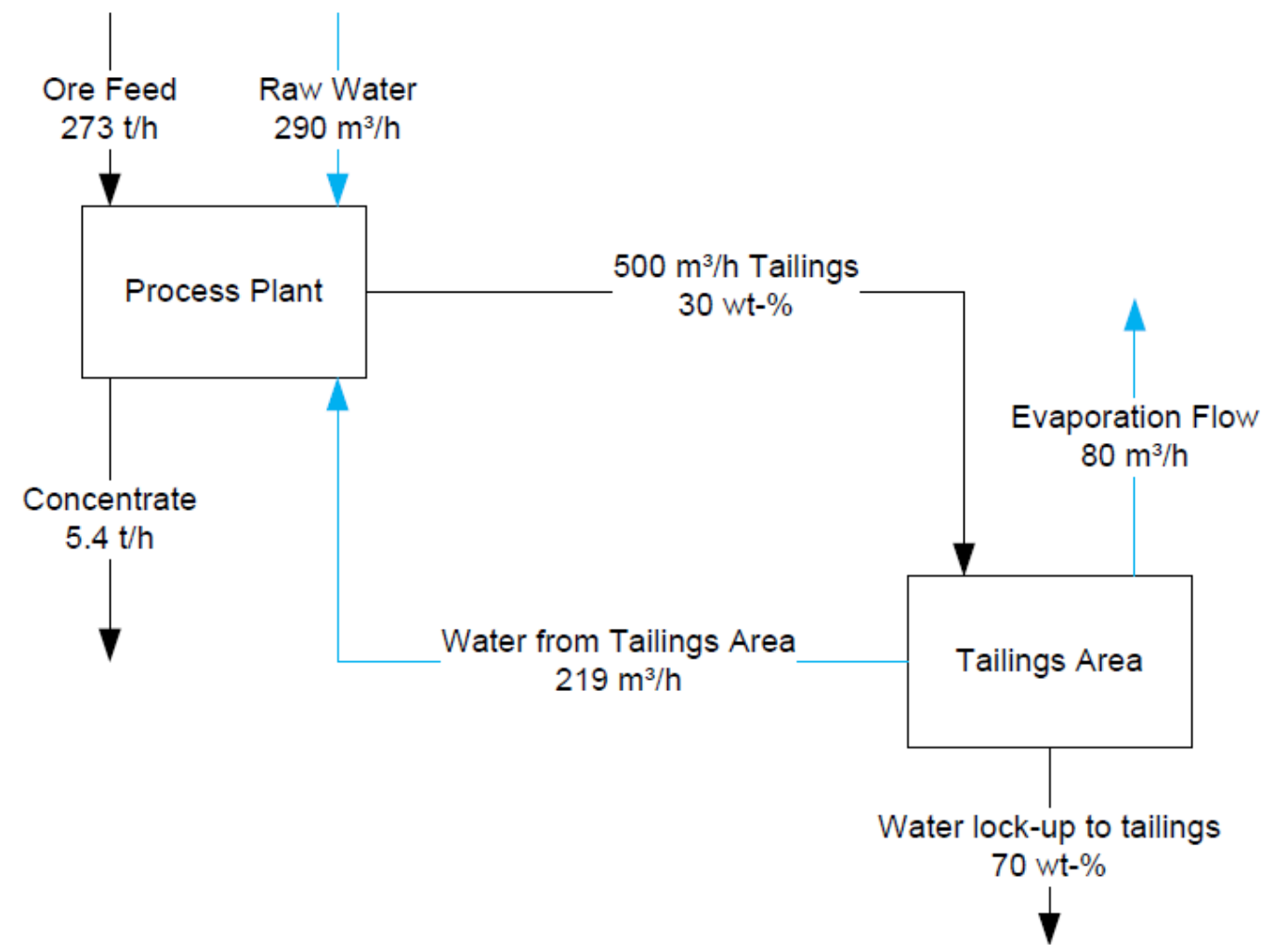

Figure 4 Flow diagram of Scenario 1

\subsubsection{Water flows for Scenario 2}

In this scenario there are more flows because of the thickener facility. The tailings flow from the process plant is the same as in Scenario 1. From the thickener, two flows start: the tailings thickener overflow $\left(384 \mathrm{~m}^{3} / \mathrm{h}\right)$ that is reclaimed to the process plant, and the thickener underflow $\left(116 \mathrm{~m}^{3} / \mathrm{h}\right)$ that is discharged into the tailings area. Part of the tailings water is evaporated $\left(38 \mathrm{~m}^{3} / \mathrm{h}\right)$ and another part reclaimed to the process plant $\left(4 \mathrm{~m}^{3} / \mathrm{h}\right)$. The surface pond in this scenario is 87.18 ha. As a result, the thickened method consumes $877,215 \mathrm{~m}^{3}$ of water per year. 
The flocculants for the thickening of sludge mining are potable. Nalco 8181 (Nalco 2013) and Magnafloc333 (Ciba 2013) are some examples of flocculants used in these processes. They are not pollutants because they are nonionic, so they are not diluted in water. Therefore, they do not have an impact on the degradation of water quality. However, as discussed above, this study will only consider water consumption, not its quality.

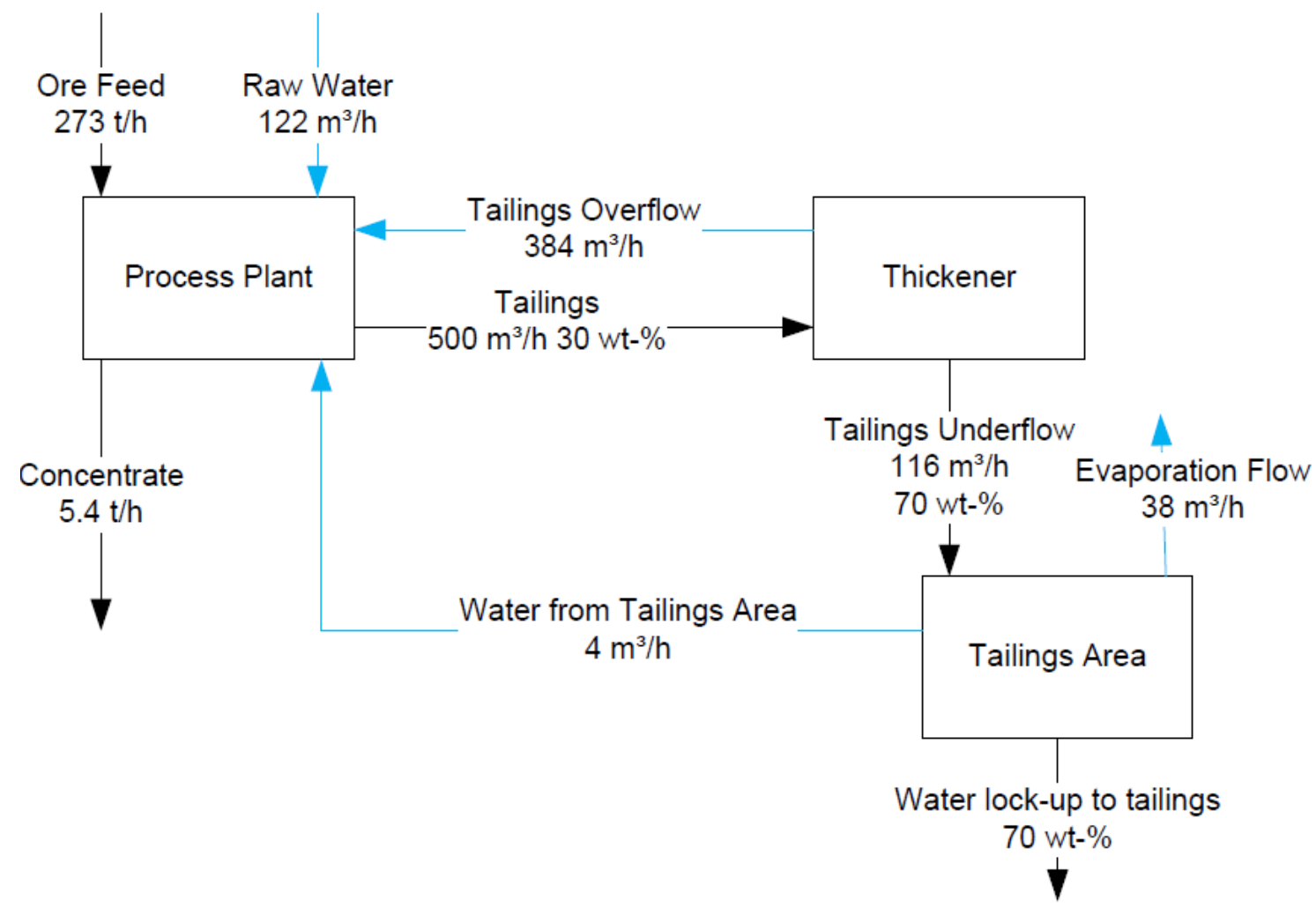

Figure 5 Flow diagram of Scenario 2

\subsection{Water Footprint Impact Assessment}

The water scarcity index (WSI) considers availability and demand for water and cannot be determined based upon climate alone. For example, if a mine is thinking of settling in a dry area, it initially has high water availability because there are no more competitors but the new demand for water will increase the overall general regional demand for water and the region's WSI (Northey et al. 2014). It is used in lifecycle impact assessment as a general characterisation factor (Brown \& Matlock 2011).

The WSI has been determined by the tool Google Earth that ETH facilitates in its web (ETH 2014). For Belo Horizonte in Minas Gerais, Brazil, it is 0.0203 . So the Scarcity Water Footprint is $42,395 \mathrm{~m}^{3}$ of water per year for conventional tailings management and $17,807 \mathrm{~m}^{3}$ of water per year for thickened tailings. However, if these scenarios are moved to a more arid region, the scarcity water footprint will increase. For example, if the mine is relocated in Atacama Desert, Chile, the WSI was 1 , so the results were $2,088,445 \mathrm{~m}^{3}$ of water per year for conventional tailings management and $877,215 \mathrm{~m}^{3}$ of water per year for thickened tailings. 


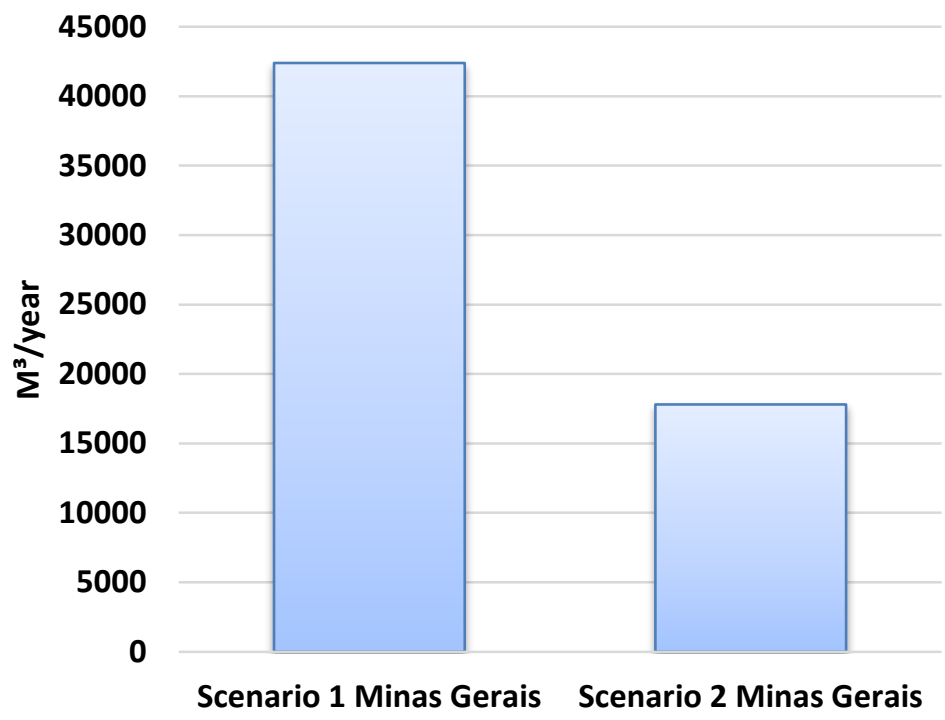

Figure 6 The scarcity water footprint of both scenarios in Minas Gerais

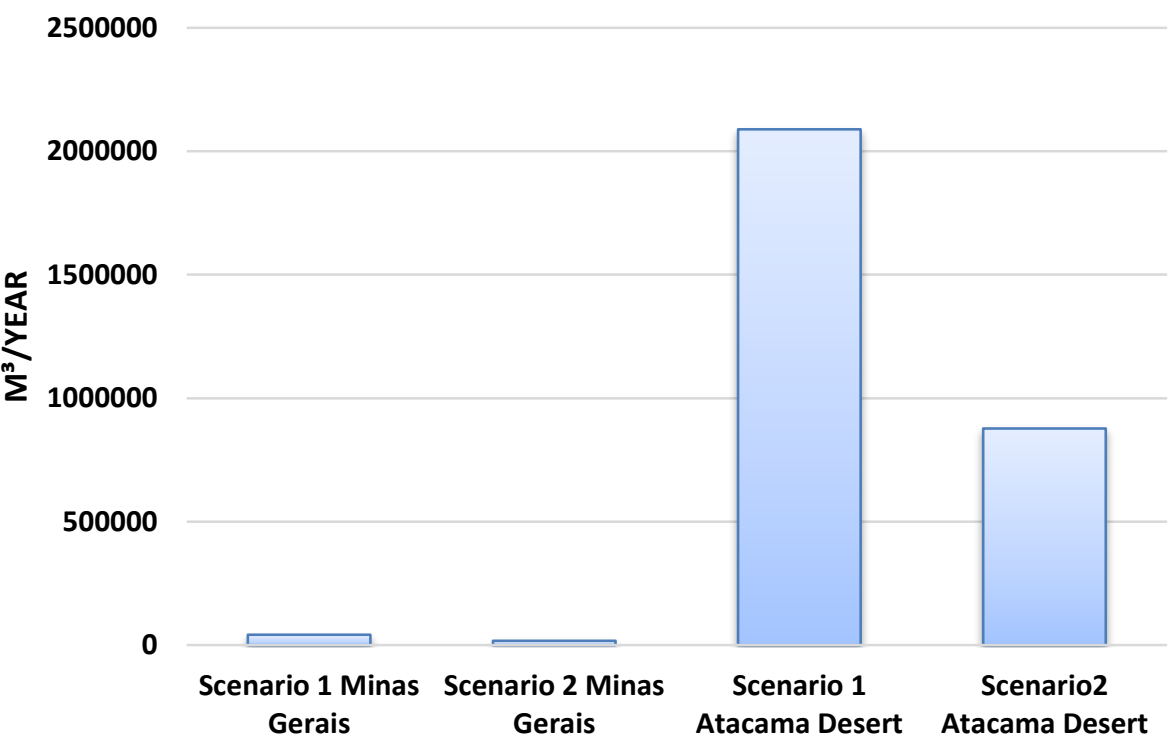

Figure 7 The scarcity water footprint of both scenarios in different localisations

Figure 6 shows that thickened tailings could save an important amount of water; therefore, the scarcity water footprint is going to get a better score in thickened tailings. On the other hand, in Figure 7, it is evident that the water savings are crucial in places such as the Atacama Desert. The scarcity footprint comparison between both localisations shows that the Minas Gerais scores are insignificant.

\subsection{Interpretation}

Any industrial process aims to achieve the least amount of inputs. If the input is water and the facilities are located in a water-scarcity region, this will be a more pressing industry target. Therefore, a saving of 2 million cubic metres of water input because of a new tailings management technique is a great advantage.

The Minas Gerais region has a tropical climate; the availability of water is abundant. Because of this, the impact of reducing the water footprint of a process does not have the same impact as if it were a region with a water scarcity. This is the case of some mines located in Chile, Australia or South Africa. 
In Minas Gerais localisation, due to a very low WSI, it is expected that the basin can maintain its level of recharge being a sustainable situation for the mine's production.

However, from a global perspective, the reduction of every process water footprint means a lesser global water footprint and this fact is beneficial to everybody. Because of this, it must search for the application of the best available techniques in mining, as paste, which allows reducing the water footprint of iron ore production.

\section{$4 \quad$ Conclusions}

The strain on the world's water resources is becoming more acute, so it is necessary to improve water management in order to reach a sustainable development. Due to this fact, the mining industry must change conventional management and apply the best available techniques.

Paste and thickened tailings are undergoing a surge of popularity, as technology is providing a great promise for improved tailings disposal with regard to water consumption. In order to know which of these techniques is more suitable, it is necessary to have a sustainability assessment methodology. A water footprint indicator, which shows the relation between human consumption and water usage as well as between global trading and water resource management, is the most suitable methodology.

Once conventional and thickened tailings disposal have been assessed in Minas Gerais, it is known that it is possible to save almost 2 million cubic metres of water input because of thickened tailings disposal. This saving is possible due to the recovery of $75 \%$ of the water process used in the process plant. Because of this, the scarcity water footprint for Scenario 2 (thickened tailings) is much lower than the Scenario 1 (conventional tailings). Although there is no water scarcity in this part of Brazil, the sustainability assessment conducted shows that thickening tailings are a lower risk than conventional tailings disposal.

However, when the location of the mine is moved to an arid place as the Atacama Desert, the scarcity water footprint is more acute and the differences between final scores are very relevant. Therefore, thickened tailings could be a very good option for those mines located in a place with high WSI.

It is, however, advisable not to forget that the water footprint assessment alone is not enough to be used to describe the overall potential environmental impacts of products, processes or organisations. A complete lifecycle assessment should be done.

\section{References}

Berger, M \& Finkbeiner, M 2010, 'Water footprinting: how to address water use in life cycle assessment?', Sustainability, vol. 2, no. 4, pp. 919-944.

Brown, A \& Matlock, MD 2011, 'A review of water scarcity indices and methodologies', The Sustainability Consortium, University of Arkansas, Tempe.

Ceres 2010, Murky waters? Corporate reporting on water risk: a benchmarking study of 100 companies, prepared by B Barton, Ceres, Boston.

Ciba 2013, Water Treatments. Anexo 2: hoja de seguridad floculante, coagulante y nutriente, Ciba Especialidades Químicas Ltda., Santiago, viewed 11 March 2015, http://www.e-seia.cl/archivos/Anexo_2_HDS.pdf

Doka, G 2009, Life cycle inventory data of mining waste: emissions from sulfidic tailings disposal, Doka Life Cycle Assessments, Zürich.

ETH 2014, Water stress index (WSI) for use in water footprinting and endpoint characterization factors of water consumption for use in LCA, ETH Zürich: IfU - El99+, Zürich, viewed 1 October 2014, http://www.ifu.ethz.ch/ESD/downloads/El99plus

Fernández-Iglesias, A, Correa de Araujo, A, Andrés, S, Xuan, W, Luiña, R \& Álvarez, V 2013, 'Study of environmental feasibility of paste and thickened tailings by life-cycle assessment (LCA)', in RJ Jewell \& AB Fourie (eds), Proceedings of the 16th International Seminar on Paste and Thickened Tailings, Australian Centre for Geomechanics, Perth, pp. 349-364.

Hendrix, J 2012, Gold mining and the use, quality and availability of water, University of Nebraska, Lincoln.

Hoekstra, AY, Chapagain, AK, Aldaya, MM \& Mekomen, MM 2011, The water footprint assessment manual: setting the global standard, viewed 11 March 2015, www.waterfootprint.org/downloads/TheWaterFootprintAssessmentManual.pdf, Water Footprint Network, Enschede.

Hoekstra, AY, Chapagain, AK, Aldaya, MM \& Mekomen, MM 2009, Water footprint manual: state of the art 2009 , viewed 11 March 2015, www.waterfootprint.org/downloads/WaterFootprintManual2009.pdf, Water Footprint Network, Enschede.

Hoekstra, AY \& Chapagain, K 2008, Globalization of water: sharing the planet's freshwater resources, Blackwell Publishing, Oxford. 
International Organization for Standardization 2014, ISO 14046: Environmental Management - Water Footprint - Principles, Requirements and Guidelines, ISO, Geneva.

International Organization for Standardization 2006, ISO 14040: Environmental Management - Life Cycle Assessment - Principles and Framework, ISO, Geneva.

Jeswani, KH \& Azapagic, A 2011, 'Water footprint: methodologies and a case study for assessing the impacts of water use', Journal of Cleaner Production, vol. 19, no. 12, pp. 1288-1299.

Jewell, RJ \& Fourie, AB 2006, Paste and thickened tailings - a guide, 2nd edn, Australian Centre for Geomechanics, Perth.

Koehler, A 2008, 'Water use in LCA: managing the planet's freshwater resources', International Journal of Life Cycle Assessment, vol. 13, no. 6, pp. 451-455.

Kounina, A, Margni, M, Bayart, JB, Boulay, AM, Berger, M, Bulle, C, Frischknecht, R, Koehler, A, Milà i Canals, LI, Motoshita, M, Núñez, M, Peters, G, Pfister, S, Ridoutt, B, Zelm, R, Verones, F \& Humbert, S 2013, 'Review of methods addressing freshwater use in life cycle inventory and impact assessment', International Journal of Life Cycle Assessment, vol. 18, no. 3 , pp. 707-721.

Kulczycka, J 2008, LCA for minimisation of environmental impact of wastes from zinc and lead industry, Polish Academy of Sciences, Krakov.

Milà i Canals, LI, Chenoweth, J, Chapagain, A, Orr, S, Antón, A \& Clift, R 2009, 'Assessing freshwater use impacts in LCA part I: inventory modelling and characterisation factors for the main impact pathways', International Journal of Life Cycle Assessment, vol. 14, no. 1, pp. 28-42.

Motoshita, M, Itsubo, N, Inaba, A 2010, 'Development of impact factors on damage to health by infectious diseases caused by domestic water scarcity', International Journal of Life Cycle Assessment, vol. 16, no. 1, pp. 65-73.

Nalco 2013, Hoja técnica Nalco 8181, floculante potable, Asociación Nacional de la Industria Química, Mexico, viewed 2 January 2013, http://www.aniq.org.mx/pqta/pdf/NALCO\%208181\%20(HT).pdf

Northey, SA, Haque, N, Lovel, R \& Cooksey, MA 2014, 'Evaluating the application of water footprint methods to primary metal production systems', Minerals Engineering, vol. 69, pp. 65-80.

Peck, P 2007, 'Avoiding tailings dam failures - good practice in prevention', Workshop on the Safety of Tailings Management Facilities, UNEP GRID Arendal and IIIEE , Lund University, Lund.

Pfister, S, Koehler, A, Hellweg, S 2009, 'Assessing the environmental impacts of freshwater consumption in LCA', Environmental Science \& Technology, vol. 43, no. 11, pp. 4098-4104.

Rowe, J 2012, The future of water in the mining industry, International Mine Water Association, viewed 10 October 2014, https://www.imwa.info/docs/imwa_2012/IMWA2012_Rowe_425.pdf

Society for Mining, Metallurgy and Exploration, Inc. 2012, Mining and the use, quality and availability of water, SME, Englewood, viewed 6 October 2014, www.smenet.org/docs/public/MiningandtheUseQualityandAvailabilityofWater.docx

Triantou, AD 2009, 'Carbon, energy and water footprint of three Akzo Nobel internal sizing chemicals: a cradle to gate LCA related study', Master of Science thesis, Royal Institute of Technology.

Vörösmarty, CJ, Green, P, Salisbury, J \& Lammers, RB 2000, 'Global water resources: vulnerability from climate change and population growth', Science, vol. 289 , no. 5477 , pp. 284-288.

VTT Technical Research Centre of Finland 2014, Water footprint, VTT Technical Research Centre of Finland, viewed 20 October 2014, www.vtt.fi/research/technology/water_footprint.jsp?lang=en

Water Footprint Network 2011, WaterStat, Water Footprint Network, Enschede, viewed 5 October 2014, www.waterfootprint.org

World Business Council for Sustainable Development 2010, The global water tool, WBCSD, Geneva, viewed 3 October 2010, http://www.wbcsd.org/work-program/sector-projects/water/global-water-tool.aspx

Wennberg, T 2010, 'Transporting highly concentrated slurries with centrifugal pumps: The thickened minerals tailings example', Licentiate thesis, Luleå University of Technology.

United Nations World Water Assessment Programme 2009, 'Water in a changing world', UNESCO Publishing, Paris, viewed 11 March 2015, webworld.unesco.org/water/wwap/wwdr/wwdr3/pdf/WWDR3_Water_in_a_Changing_World.pdf 
